\title{
EDUCAĈ̃̃O EM SAÚDE E MEIO AMBIENTE: UM DESAFIO DE VIVẾNCIA E REFLEXÃO DA PRÁTICA DOCENTE
}

\author{
André Luis de Souza FERREIRA ${ }^{1}$ \\ Flavia Karolina Pereira Barreto BETTIOL ${ }^{2}$ \\ Victor Hugo de Oliveira HENRIQUE ${ }^{3}$ \\ Edward Bertholine de CASTRO ${ }^{4}$
}

RESUMO: A educação está em constante transformação e o momento histórico no qual vivemos exige uma reflexão sobre a inclusão de idéias inovadoras no atual modelo de ensino. Este artigo objetiva discutir a realização de um minicurso aplicado na área de Saúde e Meio Ambiente envolvendo atividades dinâmicas no ensino de Biologia, contribuindo para a formação e construção do conhecimento. A metodologia baseou-se na modalidade didática expositiva dialógica aliada a prática dinamizada no processo de ensino aprendizagem. Os resultados mostram que há garantias de eficiência na aplicação de práticas dinâmicas, para que ocorra o aprendizado significativo sobre o tema desenvolvido.

PALAVRAS-CHAVE: Ensino Médio. Biologia. Metodologias. Didática.

\section{INTRODUÇÃO}

A educação está em constante transformação e o momento histórico no qual vivemos exige uma reflexão sobre a inclusão de idéias inovadoras no atual modelo de ensino. $\mathrm{O}$ encorajamento e o desenvolvimento de uma aprendizagem significativa sobre temas voltados à realidade e cotidiano dos alunos como, por exemplo, Saúde e Meio Ambiente, se fazem necessários por propiciarem melhor compreensão da evolução do conhecimento, das transformações que ocorrem na natureza e da ação positiva e negativa do homem sobre o ambiente natural. Nesse sentido, o ensino de Ciências, principalmente o de biologia, deve estimular o raciocínio e o conhecimento do aluno, de maneira que não seja apenas informativo.

A necessidade por desenvolver aulas mais dinâmicas e atrativas para o ensino de Biologia tem sido uma tarefa árdua ao longo do tempo, visando a melhoria do processo

\footnotetext{
${ }^{1}$ Graduando em Ciências Biológicas. UFMT - Universidade Federal de Mato Grosso - Instituto de Biociências. Bolsista do Programa de Iniciação à Docência PIBID. Cuiabá - MT - Brasil. 78060-900 aluissouza@hotmail.com

${ }^{2}$ Graduanda em Ciências Biológicas. UFMT - Universidade Federal de Mato Grosso - Instituto de Biociências. Bolsista do Programa de Iniciação à Docência PIBID. Cuiabá - MT - Brasil. 78060-900 fk_tv@hotmail.com

${ }^{3}$ Pós-Graduando (Mestrado) em Educação. UNESP - Universidade Estadual Paulista - Departamento de Educação. Rio Claro - SP - Brasil. 13506-900 - hugo31_oh@ hotmail.com

${ }^{4}$ UFMT - Universidade Federal de Mato Grosso - Instituto de Biociências. Depatamento de Zoologia e Biologia Geral. Cuiabá - MT - Brasil.78060-900 - vava67@ gmail.com
} 
ensino-aprendizagem, o desenvolvimento do indivíduo e sua socialização. E analisando esse momento histórico, Behrens (2003, p.17) ressalta que, “[...] um dos grandes méritos deste século é o fato de os homens terem despertado para a consciência da importância da educação como necessidade preeminente para viver em plenitude como pessoa e como cidadão na sociedade”. Diante disso, verifica-se que a escola deve ter como objetivo a formação de indivíduos sensibilizados e críticos, ao qual possam utilizar o conhecimento adquirido em seu dia a dia, favorecendo, positivamente, a educação básica.

Todavia, observa-se no ensino de Biologia, que nem sempre o aluno consegue relacionar a teoria desenvolvida em sala com a realidade a sua volta. Considerando que a teoria é feita de conceitos que são abstrações da realidade (SERAFIM, 2001), compreendemos que o aluno que não é capaz de assimilar ou reconhecer o conhecimento adquirido em situações do seu cotidiano, não conseguirá entender a teoria. Segundo Freire (1997, p.21), "para compreender a teoria é preciso experienciála".

Diante dessa necessidade, torna-se imprescindível a utilização de práticas dinâmicas que estimulem o conhecimento dos alunos diante à temática desenvolvida. Sendo assim, a realização de dinâmicas em sala de aula representa uma excelente ferramenta para que o aluno construa o conhecimento estabelecendo a relação entre teoria e prática.

$\mathrm{O}$ processo de ensino-aprendizagem aliado às práticas dinamizadas também é discutida por Bazin (1987) que, em uma experiência de ensino não formal de Ciências, aposta na maior significância desta metodologia em relação à simples memorização da informação, método tradicionalmente empregado nas salas de aula.

As análises aqui expressas quanto à utilização de metodologias de ensino que incluam, não apenas a teoria, mas também atividades dinâmicas para o ensino de Biologia, principalmente em temas importantes como Saúde e Meio Ambiente, revelam a sua importância na construção do conhecimento, sendo este o objetivo deste trabalho.

\section{MATERIAIS E MÉTODOS}

Este trabalho foi desenvolvido na Escola Marechal Eurico Gaspar Dutra, localizada no município de Barra do Garças - Mato Grosso, ao qual foi aplicado um 
minicurso, para os alunos do primeiro ano do Ensino Médio matutino, com a temática "Saúde e Meio Ambiente: que interação é essa?".

O minicurso foi realizado no período de 4 à 8 de agosto de 2014, sendo dividido em cinco módulos, abordando os seguintes temas: 1 - Meio ambiente natural; 2 - Meio ambiente sustentável; 3 - Degradação e Poluição ambiental; 4 - Saúde e Meio ambiente; e 5 - Saúde e Sexualidade.

As aulas teóricas foram realizadas, com auxílio de datashow, quadro branco e caneta marcadora, baseando-se na modalidade didática expositiva dialógica aliada à prática dinamizada no processo de ensino aprendizagem. Essa modalidade caracterizouse pela exposição de conteúdos com a participação ativa dos alunos, considerando o conhecimento prévio dos mesmos, sendo o professor o mediador para que os alunos pudessem questionar, interpretar e discutir o objeto de estudo.

Sendo assim, uma aula expositiva dialogada o professor precisa contextualizar o tema de modo que mobilize as estruturas mentais do aluno para que este articule informações que já traz consigo com as que serão apresentadas. Nesse sentido, a aplicação das aulas expositivas e das práticas dinâmicas tornaram-se uma metodologia de ensino dinâmica e diferenciada, envolvendo os alunos em questões relacionadas ao seu dia a dia.

Durante o período do minicurso foram aplicadas atividades que estimulassem o raciocínio e o conhecimento dos alunos, através de perguntas, debates, reflexões e atividades práticas envolvendo o ser humano e o meio ambiente, procurando-se analisar as idéias dos alunos durante todo o processo de ensino aprendizagem sobre o tema desenvolvido.

Os materiais utilizados para a produção das atividades dinâmicas foram simples e de fácil acesso como, por exemplo, cartolinas, cola e canetas esferográficas para a construção de cartões com perguntas e frases a serem completadas, além de recortes de ambientes naturais para uma dinâmica envolvendo grupos de alunos em diferentes ambientes naturais na qual estes sofriam degradações sendo os animais obrigados a superpopular outro ambiente, ocasionando mortes ou disputas por recursos, ou mesmo causando doenças em humanos devido a migração de animais para as cidades.

$\mathrm{O}$ instrumento $\mathrm{n}^{\circ} 1$ utilizado como atividade dinâmica foi um conjunto de tirinhas de papel contendo frases imcompletas sobre o meio ambiente (Quadro 1), encontradas no sitio de dinâmicas sobre o meio ambiente, para que os alunos 
completassem com o seu pensamento em relação a frase proposta e em seguida ler a frase completa para a turma.

Quadro 1 - Frases incompletas utilizadas como atividade dinâmica em Biologia

\begin{tabular}{|c|c|}
\hline 1) Quando penso no futuro do meio ambiente, eu vejo...; & 16) Neste momento, estou muito preocupado com a situação da...; \\
\hline $\begin{array}{l}\text { 2) Quando entro num ambiente sujo, com muito lixo no chão, eu penso } \\
\text { que...; }\end{array}$ & 17) Detesto quando alguém diz que...; \\
\hline 3) Em minha opinião o meio ambiente é...; & 18) Às vezes, eu me sinto como se...; \\
\hline 4) O desmatamento é triste, porque...; & 19) Conscientização ambiental é...; \\
\hline 5) Tenho vergonha enorme de...; & 20) Quando falam em poluição eu...; \\
\hline 6) Eu considero problemas ambientais quando...; & 21) A vida é um bem precioso que deve ser...; \\
\hline $\begin{array}{l}\text { 7) Quais são os individuos prejudicados com as ações desordenadas do } \\
\text { homem são...; }\end{array}$ & 22) Eu colaboro com a natureza quando...; \\
\hline 8) Quando leio/vejo nos jomais notícias sobre catástrofes ambientais, eu...; & 23) No dia da água eu...; \\
\hline 9) Em minha opinião o ambiente natural é...; & 24) Quando penso em saúde eu...; \\
\hline 10) A meu ver, a reciclagem é importante para o meio ambiente e...; & 25) Quando vou ao supermercado, eu...; \\
\hline 11) Quando alguém desperdiça áğua eu...; & 26) Sinto-me mais feliz quando o meio ambiente...; \\
\hline 12) No dia do meio ambiente eu...; & 27) Eu me sinto integrado à natureza quando...; \\
\hline 13) Tenho muito medo de...; & 28) Quando estou em um parque/praça, eu gosto de...; \\
\hline $\begin{array}{l}\text { 14) O que mais me entristece é...; } \\
\text { 15) Catástrofe ambiental é quando...; }\end{array}$ & 29) O que mais me deixa triste em relação ao meio ambiente é... \\
\hline
\end{tabular}

Fonte: Rocha (2012), organizado pelos autores.

$\mathrm{O}$ instrumento $\mathrm{n}^{\mathrm{o}} 2$ foi um conjunto de cartões contendo perguntas sobre a temática desenvolvida (Quadro 2), a qual os alunos deveriam se organizar e promover um debate, escolhendo um colega e lançando a pergunta retirada do baralho para que este pudesse responder de acordo com o seu conhecimento. As perguntas utilizadas para a realização da dinâmica foram, também, de grande importância para a construção do conhecimento e um momento para sanar dúvidas referente a conceitos basicos envolvendo o homem e ambiente natural, estas encontradas no sitio de dinâmicas sobre o meio ambiente. 
Quadro 2 - Perguntas sobre o meio ambiente

\begin{tabular}{|c|c|}
\hline 1) O que você faz para poupar água?; & 16) Você acha que a escola colabora com o meio ambiente?; \\
\hline 2) O que você pode fazer para poupar a energia elétrica?; & 17) Você se preocupa com o meio ambiente? Por quê?; \\
\hline 3) O que você pode fazer para diminuir a produção de lixo?; & $\begin{array}{l}\text { 18) Qual seria a sua reação ao ver um indivíduo derrubar uma } \\
\text { árvore? Por quê?; }\end{array}$ \\
\hline 4) O que você faz para colaborar com o meio ambiente?; & $\begin{array}{l}\text { 19) O que você faz ao ver alguém jogar lixo pela janela do } \\
\text { ônibus/carro?; }\end{array}$ \\
\hline 5) O que você mais gosta na natureza?; & $\begin{array}{l}\text { 20) O que você pensa quando alguém the diz que reciclar é bobeira? } \\
\text { Por quê?; }\end{array}$ \\
\hline 6) Você se considera parte da Natureza? Por quê?; & 21) Qual a importância de se estudar o meio ambiente?; \\
\hline 7) Qual a importância da água?; & 22) Você acha que podemos ser donos dos animais? Por quê?; \\
\hline 8) Qual é o maior problema ambiental para você?; & $\begin{array}{l}\text { 23) Você acha que as plantas nos auxiliam na nossa sobrevivência? } \\
\text { Explique.; }\end{array}$ \\
\hline 9) A pobreza é um problema ambiental? Por quê?; & $\begin{array}{l}\text { 24) Por que devemos preservar a qualidade da água no nosso } \\
\text { planeta?; }\end{array}$ \\
\hline 10) A superpopulação é um problema ambiental? Por quê?; & $\begin{array}{l}\text { 25) A exploração do meio ambiente deve ocorrer de maneira } \\
\text { limitada? Explique.: }\end{array}$ \\
\hline 11) O que você pensa sobre pássaros em gaiolas?; & 26) Para você, o que significa "ser ambientalmente correto"?; \\
\hline 12) O que você pensa sobre o consumismo?; & 27) Você acha que a sua cidade tem poluição? Cite exemplos.; \\
\hline $\begin{array}{l}\text { 13) Como você se sente quando vê pessoas com más posturas } \\
\text { ambientais?; }\end{array}$ & 28) De que forma a poluição te afeta?; \\
\hline $\begin{array}{l}\text { 14) Para você, quais as diferenças entre viver em um ambiente } \\
\text { urbano (cidade) e um ambiente rural (campo)?; }\end{array}$ & 29) De que forma as suas atitudes podem ajudar o meio ambiente?; \\
\hline 15) Para você, por que é tão difícil mudar hábitos e atitudes?; & 30) A educação ambiental é importante? Por quê? \\
\hline
\end{tabular}

Fonte: Rocha (2012), organizado pelos autores.

$O$ instrumento $\mathrm{n}^{\mathrm{o}} 3$ foi caracterizado pela utilização de recortes contendo paisagens naturais, a qual os alunos se dividiriam em três grupos, cada um representando um ambiente natural e os alunos seriam os seres viventes daquele ambiente. E através da ação do homem ou por fatores naturais seriam demonstrados a degradação de um ambiente e qual seria a resposta dos seres vivos a essa ação, estimulando os alunos a pensarem em procurar outro ambiente para sobreviver, podendo superpopular este ambiente ocasionando disputa por recursos e espaço ou até mesmo a morte do indivíduo. E em se tratando do ser humano, a necessidade de se construir mais imóveis, devido a superpopulação, utilizando os ambientes naturais como espaço para essa prática.

$\mathrm{O}$ instrumento $\mathrm{n}^{\circ} 4$ tratou-se de um estudo dirigido com perguntas abordando o que pensamos e sentimos em relação ao meio ambiente e a degradação ambiental (Quadro 3). O estudo dirigido permite o aluno estudar um assunto a partir de um roteiro elaborado pelo professor. O professor instrui o aluno em seu aprendizado e fornece as instruções necessárias para realizar a tarefa. O objetivo desta atividade é proporcionar condições para o aluno aprender e desenvolver a habilidade de adquirir informações além de servir como técnica de fixação do assunto abordado em aula. Este estudo foi composto com as seguintes questões: 
Quadro 3 - Estudo dirigido aplicado

\begin{tabular}{|l|l|}
\hline 1) Defina Meio ambiente. & $\begin{array}{l}\text { 6) O desmatamento da Floresta Amazônica é um dos principais } \\
\text { problemas ambientais do mundo atual. Quais os danos causados ao } \\
\text { meio ambiente devido a essa prática desenfreada? }\end{array}$ \\
2) Qual a importância de se estudar educação ambiental? & $\begin{array}{l}\text { 7) De que maneira podemos contribuir para a conservação e } \\
\text { preservação do ambiente natural? }\end{array}$ \\
$\begin{array}{l}\text { 3) Quais são os principais elementos dos ciclos } \\
\text { biogeoquímicos necessários à sobrevivência e manutenção da } \\
\text { vida no ambiente? }\end{array}$ & 8) Quais os tipos de poluição e suas consequências? \\
$\begin{array}{l}\text { 4) O que você entende por meio ambiente sustentável? } \\
\text { 5) Quais as principais consequências causadas ao meio } \\
\text { ambiente devido à ação do homem? }\end{array}$ & 9) "O rico polui por ganância e o pobre por necessidade" Explique. \\
\hline
\end{tabular}

Fonte: Rocha (2012), organizado pelos autores.

O trabalho, portanto, constituiu-se numa metodologia aliando a teoria e a prática dinamizada, promovendo uma análise qualitativa do ensino e da aprendizagem através de questionários avaliativos, onde os resultados comprovam a eficácia das aulas ministradas.

\section{RESULTADOS E DISCUSSÃO}

Com o desenvolvimento das aulas de Biologia no minicurso, apesar do prazo de observação ser curto para a análise da metodologia aplicada, verificou-se que os alunos demonstraram interesse e curiosidade no processo de aprendizagem, pois tratou-se de aulas diferenciadas com aplicação de dinâmicas instrutivas.

As aulas expositivas dialógicas se mostraram eficientes no processo de ensinoaprendizagem, onde os alunos questionam, compartilham experiências e visões de mundo, cada um de acordo com sua vivência e conhecimento prévio.

As atividades experimentais não devem ser exclusivamente realizadas em um laboratório com roteiros seguidos nos mínimos detalhes e sim, partir de um problema ou questão a ser respondida (BRASIL, 2002). As Orientações Curriculares para o Ensino Médio apontam que as atividades práticas dinâmicas ou experimentais não garante a produção de conhecimentos significativamente, mas é uma importante ferramenta para construção do mesmo.

As aulas teóricas aliadas à práticas dinâmicas são fundamentais em qualquer disciplina, fazendo com que o aluno relacione o conteúdo dado com o seu cotidiano. Como exemplo, no ensino de ciências, podemos citar os fenômenos físicos, químicos e biológicos que interagem entre si, e estão presentes no nosso dia a dia. Cabe ao 
professor buscar métodos diversos de ensino, mas que atinja seu objetivo, que é de transmitir o seu conhecimento para seus alunos (FAY, 2009). Estes se sentem mais motivados através da prática dinâmica, que difere das aulas do cotidiano, onde eles podem colocar na prática o que aprendem na teoria, havendo um maior envolvimento por parte deles durante a aprendizagem (SANTOS, 2013).

Segundo Nogueira (2009), as aulas práticas voltadas ao ensino de Ciências e Biologia deveriam assumir um papel de suma importância no Brasil, estas atividades permitem aos alunos construírem uma visão do mundo que os cercam, pois proporciona que este construa uma consciência mais crítica perante a sociedade, mas para que isso seja possível é necessário que ele tenha a oportunidade de pensar, criar e saiba questionar fazer uso do que se está sendo proposto, para que este seja atuante, construtor do próprio conhecimento.

Com as atividades dinâmicas realizadas durante o minicurso, foi averiguado que os alunos consideram importante o uso de práticas diferenciadas, pois estimula o interesse do aluno pelo conteúdo. E são essas práticas que contribuem para a dinamização das aulas.

Percebeu-se nas respostas das atividades dinâmicas e do estudo dirigido uma visão ainda ingênua em relação a conceitos sobre Saúde e Meio ambiente, pois estes compreendem também os aspectos políticos, econômicos, sociais e educacionais que devem ser trabalhados em uma visão crítica. Quanto à importância de estudar o meio ambiente e as ações do homem em prejudicá-lo, todos responderam de maneira consciente, algo que se pode considerar muito importante no ambiente escolar, pois este é um local onde se configura poder aprender coisas certas. Dessa forma, a escola adquire a função de conduzir os alunos ao pensamento crítico e reflexivo.

Ficou claro que o uso documentário sobre a temática desenvolvida, PowerPoint para exposição das aulas e aplicações de dinâmicas simples, são instrumentos que podem ser utilizados para a renovação das metodologias de ensino, enriquecendo as aulas e potencializando do processo ensino-aprendizagem. Pois, como reforçam Maia, Monteiro e Menezes (2008, p.5) “[...] só o desenvolvimento de pedagogias diferenciadas será capaz de superar o quadro de inanição da educação brasileira e colocar o ensino de ciências em uma dimensão multicultural de visão da vida.”

E por fim, a avaliação dos alunos quanto a metodologia de ensino aplicada e ao rendimento das aulas mostram-se mais claras e precisas para a confirmação do sucesso e 
comprometimento de todos no processo ensino-aprendizagem. Sendo assim, foi aplicado um questionário avaliativo ao final do minicurso.

Gráfico 1 - Aproveitamento do tempo da aula

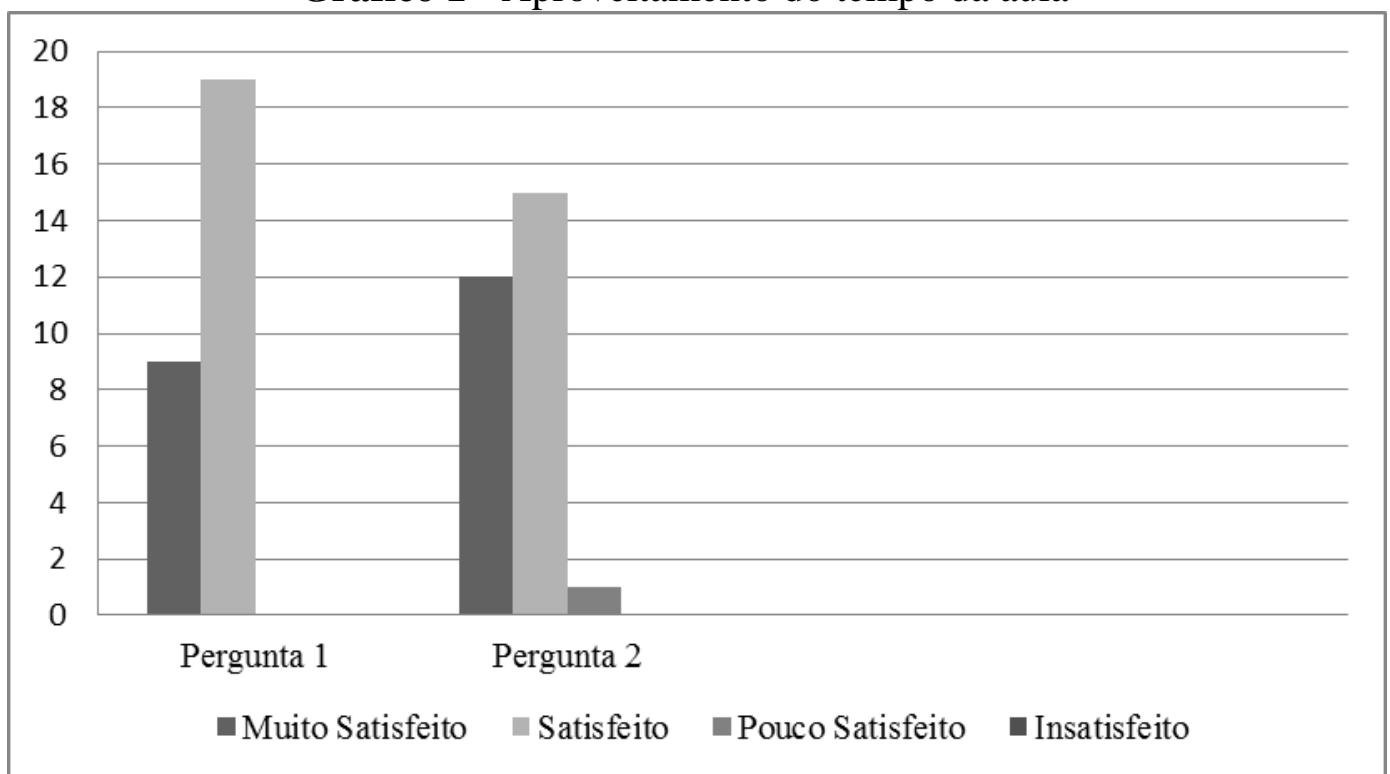

Fonte: Elaboração própria.

Nota:

Pergunta 1: O tempo de aula foi bem aproveitado pelos ministrantes da oficina?

Pergunta 2: O tempo de aula foi coerente com a proposta (20 horas aula)?

Gráfico 2 - Metodologia dos palestrantes

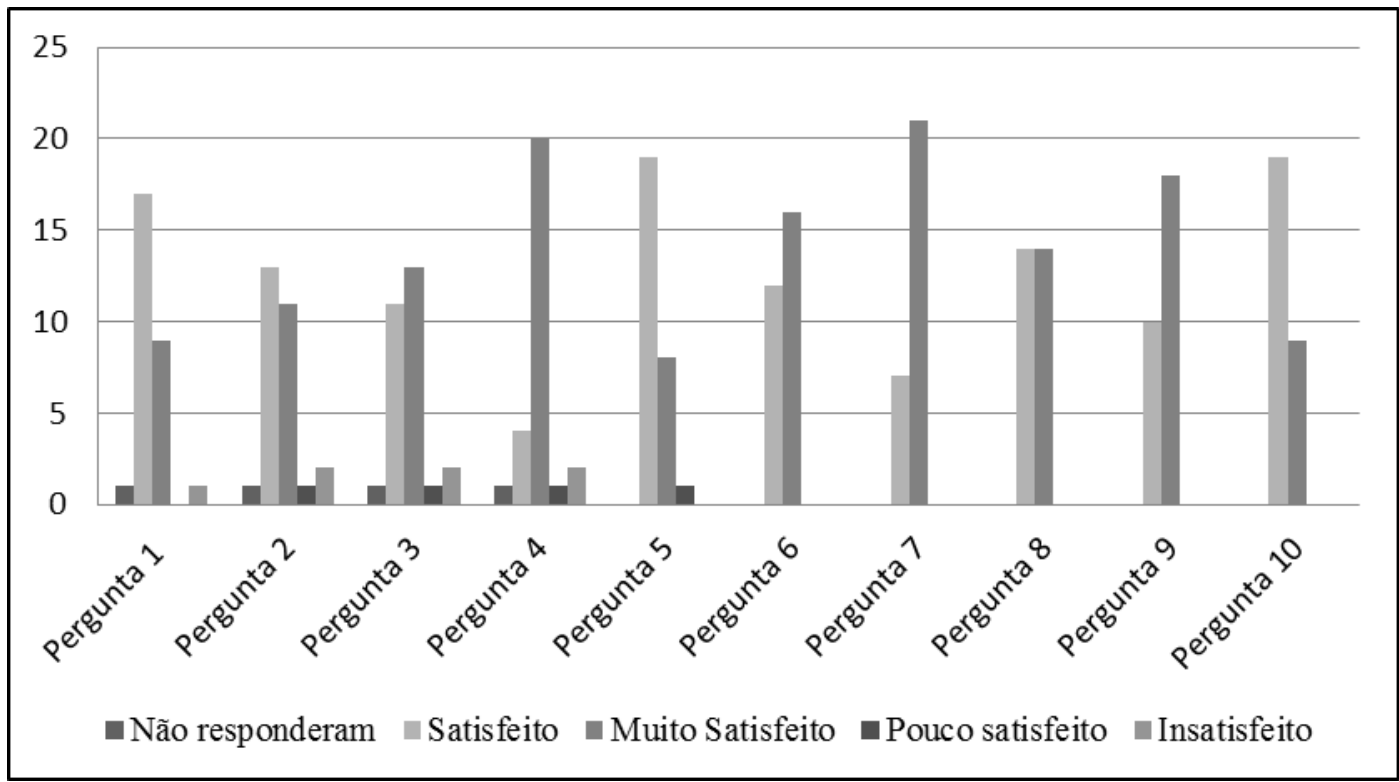

Fonte: Elaboração própria.

Nota:

Questão 1: A proposta de trabalho contemplou a participação dos alunos?

Questão 2: Houve utilização de experimentos?

Questão 3: Os experimentos utilizados contribuíram para o entendimento dos conteúdos?

Questão 4: Houve participação dos alunos nas práticas experimentais?

Questão 5: Houve contextualização do conhecimento? 
Questão 6: Foi possível perceber a aplicabilidade do conhecimento trabalhado?

Questão 7: As explicações foram claras?

Questão 8: A leitura, a escrita e a fala foram cobrados dos alunos?

Questão 9: Exercícios sobre os conteúdos foram trabalhados na sua oficina?

Questão 10: Como você avalia sua aprendizagem em relação aos conteúdos trabalhados nesta oficina?

\section{Gráfico 3 - Comunicação das aulas}

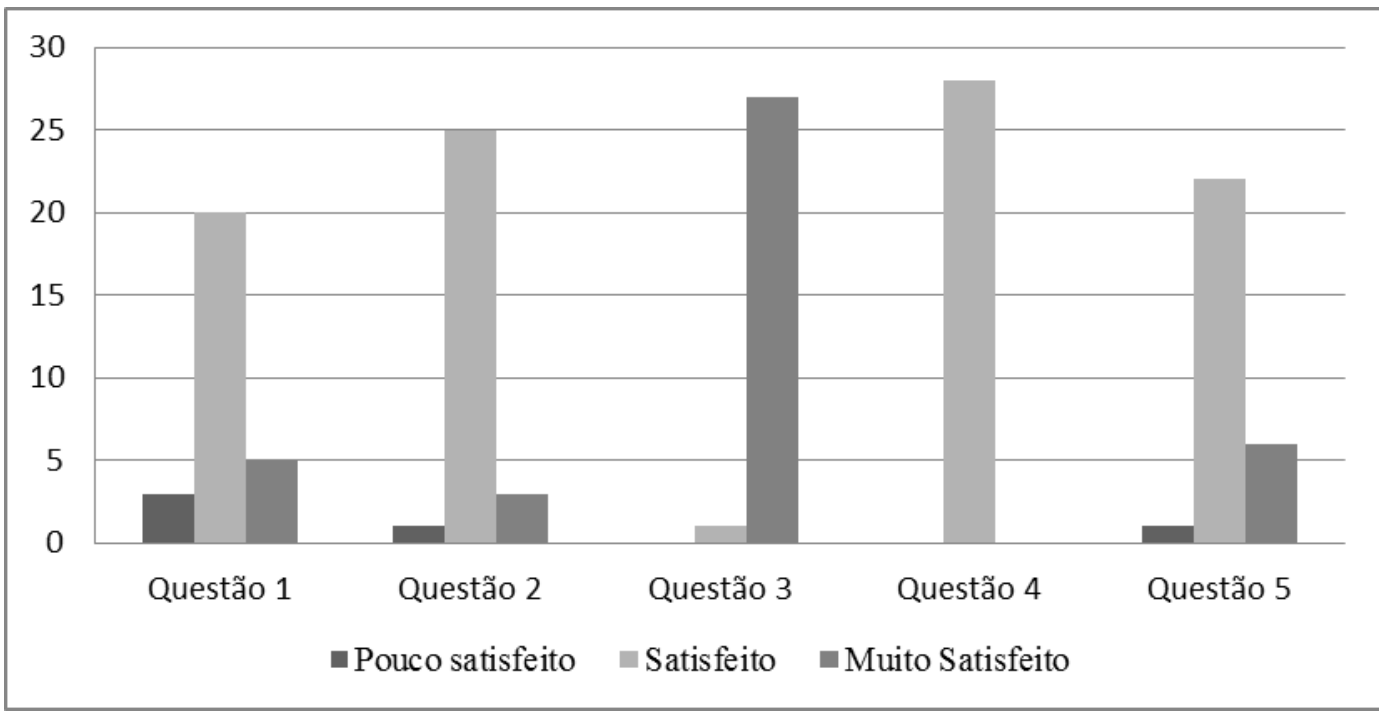

Fonte: Elaboração própria.

Nota:

Questão 1: Como foi o tom de voz dos professores?

Questão 2: A língua/linguagem foi utilizada de forma correta, sem palavrões ou palavras complicadas?

Questão 3: Houve coerência entre o falado e o escrito?

Questão 4: Houve diversificação na utilização de recursos?

Questão 5: Os professores conseguiram tornar as aulas atrativas e interessantes? 
Gráfico 4 - Postura do professor

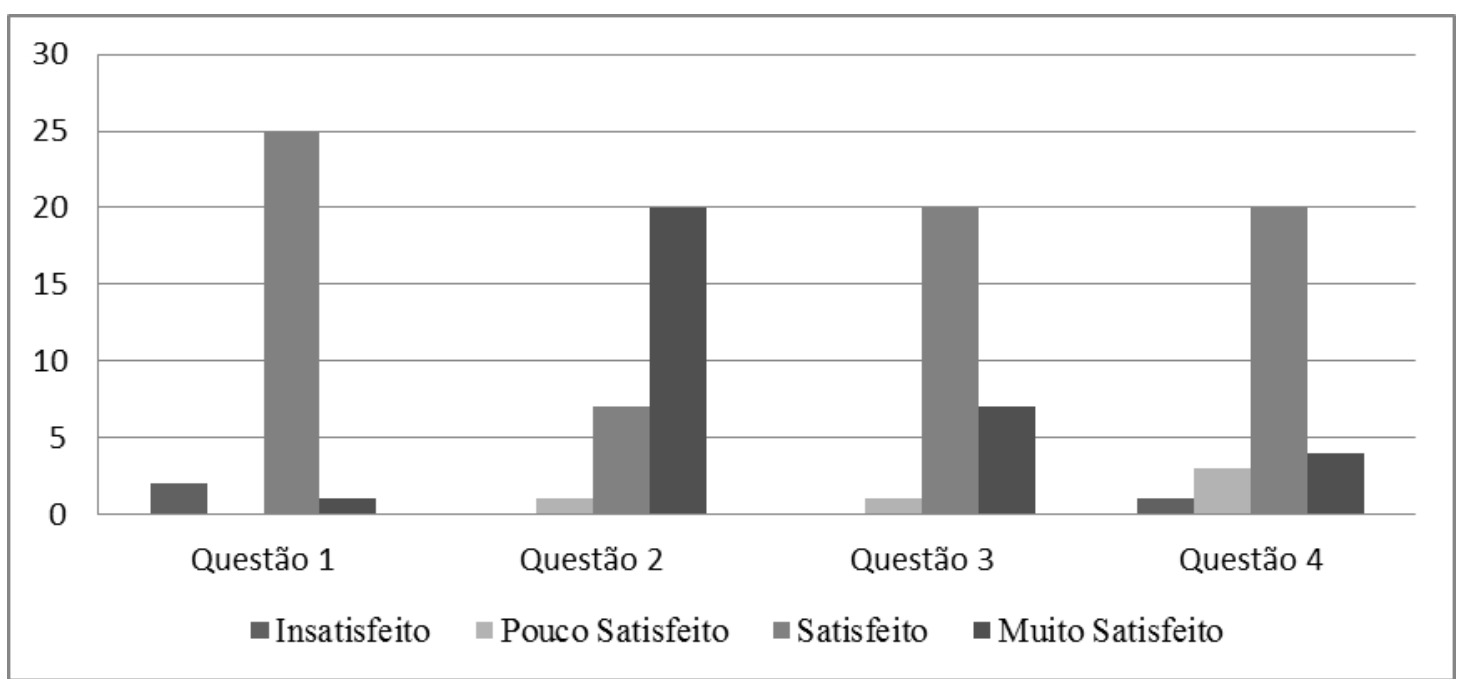

Fonte: Elaboração própria.

Nota:

Questão 1: Houve interação entre os sujeitos do processo de ensino/aprendizagem?

Questão 2: Houve domínio de sala por parte dos professores?

Questão 3: Os professores auxiliaram os alunos nas suas dificuldades?

Questão 4: Os professores foram pontuais?

Gráfico 5 - Sobre o aluno

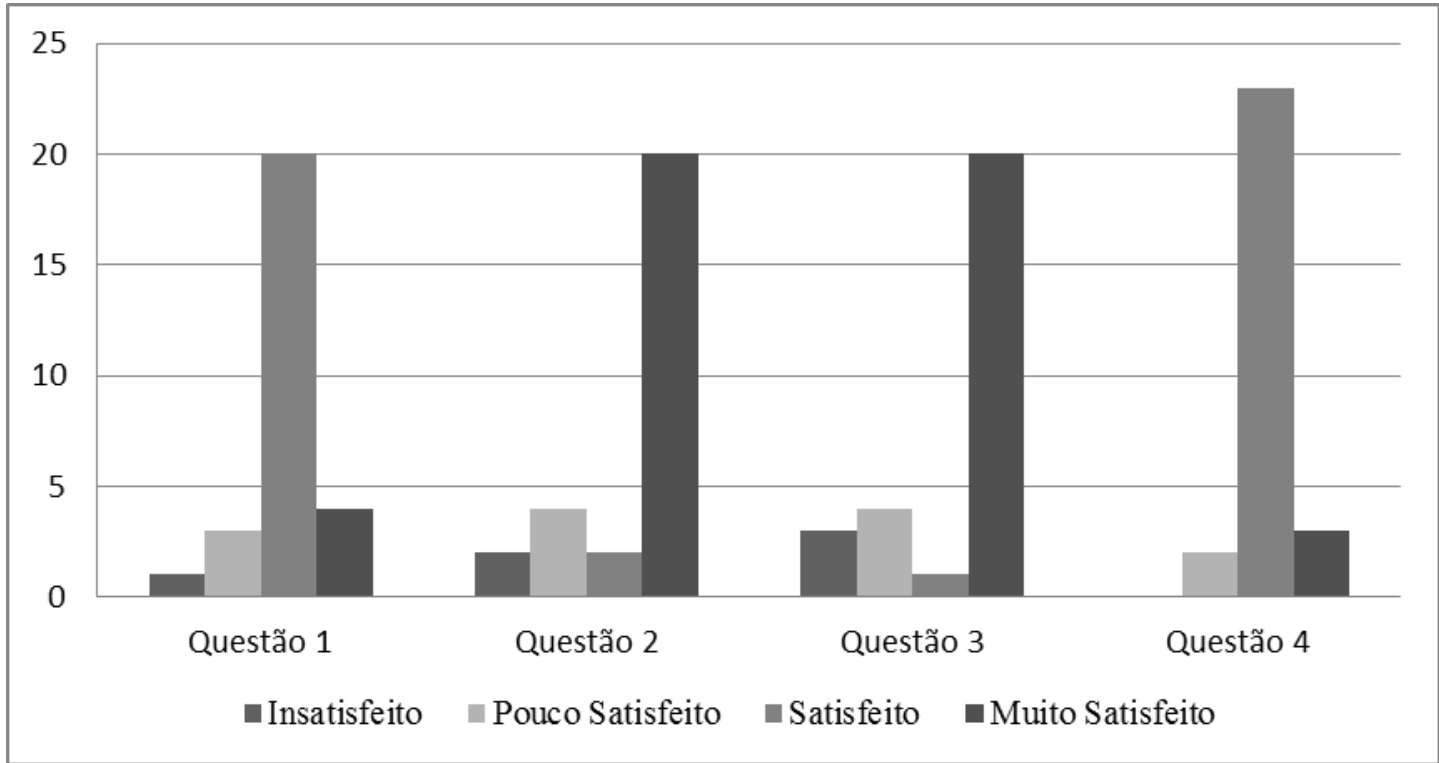

Fonte: Elaboração própria.

Nota:

Questão 1: Você ficou satisfeito com a sua participação nas atividades recomendadas pelos professores?

Questão 2: Como você avalia o seu cumprimento das regras estabelecidas pelos professores?

Questão 3: Como você avalia o seu envolvimento em conversas paralelas, com celulares e brincadeiras durante as aulas?

Questão 4: Como você avalia sua aprendizagem?

Diante do exposto, faz-se necessário que os atuais e futuros educadores se aperfeiçoem na busca por metodologias que contribuam para o desenvolvimento 
cognitivo dos alunos, como considera Libâneo (2004 p.5) cabe a estes “[...] investigar como ajudar os alunos a se constituírem como sujeitos pensantes e críticos, capazes de pensar e lidar com os conceitos, argumentar em faces de dilema e problemas da vida prática."

\section{CONSIDERAÇÕES FINAIS}

Entendemos que o uso de metodologias diferenciadas para o ensino de Ciências, principalmente no ensino de Biologia, não sejam tarefas fáceis e muitas vezes não são encaradas de maneira positiva, porém observamos na prática que o ensino de temas voltados à realidade e cotidiano do aluno, como Saúde e Meio Ambiente, torna a aprendizagem mais significativa, mesmo com uma modalidade didática simples. Tratase de uma metodologia de ensino a qual integra diferentes áreas do saber permitindo a construção do conhecimento por parte do aluno.

Vivemos em uma época em que os conhecimentos crescem de uma maneira exponencial, tornando-se praticamente impossível para uma pessoa apropriar-se de toda a informação disponível (AMORIM, 1997). Em se tratando da biologia, Giordan e Vecchi (1996), diz que há a necessidade de se trabalhar temas que não limitam a capacidade de organizar e gerenciar o fluxo contínuo de conhecimentos para que esses possam ser mobilizados na resolução de problemas e entendimento de situações que fazem parte da realidade atual.

Libâneo (2004, p.1) ressalta que a escola continua sendo o lugar de mediação cultural, cabendo aos educadores “[...] investigar como ajudar os alunos a se constituírem como sujeitos pensantes e críticos, capazes de pensar e lidar com os conceitos, argumentar em faces de dilema e problemas da vida prática.”

Torna-se imprescindível, portanto, a adoção de metodologias de ensino que contribuam significativamente no processo ensino-aprendizagem, permitindo $o$ raciocínio, a construção do conhecimento e a formação do pensamento crítico do aluno, levando este a um cenário de aprendizado suficiente para que as informações e conhecimentos adquiridos possam ser transmitidos à sociedade. 
ABSTRACT: Education is constantly changing and the historical moment in which we live requires a reflection on the inclusion of innovative ideas in the current model of education. This article aims to discuss the accomplishment of a short course applied in the area of Health and Environment dynamics involved in teaching biology activities, contributing to the formation and construction of knowledge. The methodology was based on the expository teaching dialogic mode coupled with streamlined practice in the teaching learning process. The results show that there are guarantees of efficiency in implementing dynamic practices, so that meaningful learning occurs on the theme developed.

KEYWORDS: High School. Biology. Methodologies. Didactic.

\section{REFERENCIAS}

AMORIM, A. C. R. O ensino de Biologia e as relações entre

Ciência/Tecnologia/Sociedade: o que dizem os professores e o Currículo do ensino médio?. In: ENCONTRO PERSPECTIVA DO ENSINO DE BIOLOGIA, 6., São Paulo. Anais... São Paulo: Faculdade de Educação da USP, 1997. p.74-77.

BEHRENS, M. A. O paradigma emergente e a prática pedagógica. 3.ed. Curitiba: Champagnat, 2003.

BAZIN, M. Three years of living science in Rio de Janeiro: learning from experience. Scientific Literacy Papers, Oxford, p.67-74, 1987.

BRASIL. Ministério da Educação e Cultura. Parâmetros Curriculares Nacionais: Ensino Médio. Brasília: MEC/SEF, 2002.

FAY, L. A importância da aula prática: produzindo ciências. 2009. Disponível em: <http://produzindociencias.blogspot.com.br/2009_05_01_archive.html> Acesso em: 30 ago. 2014.

FREIRE, P. Pedagogia da Autonomia. Rio de Janeiro: Paz e Terra, 1997.

GIORDAN, A.; VECCHI, G. As origens do saber: das concepções dos aprendentes aos conceitos científicos. 2.ed. Porto Alegre: Artes Médicas, 1996.

LIBÂNEO, J. C. A didática e a aprendizagem do pensar e do aprender: a teoria histórico-cultural da atividade e a contribuição de Vasili Davídov. Revista Brasileira de Educação, Rio de Janeiro, n.27, p.5-24, set./dez. 2004.

MAIA, D. P.; MONTEIRO, I. B.; MENEZES, A. P. S. Diferenciando a aprendizagem da Biologia no ensino médio, através de recursos tecnológicos. In: SEMINÁRIO NACIONAL DE EDUCAÇÃ̃O PROFISSIONAL E TECNOLÓGICA, 1., 2008, Belo Horizonte. Anais eletrônicos... Belo Horizonte, 2008. Disponível em:

$<$ http://www.senept.cefetmg.br/galerias/Arquivos_senept/anais/terca_tema5/TerxaTema 5Poster4.pdf> Acesso em: 30 ago. 2014. 
NOGUEIRA, G. Com o diferencial se constrói a diferença: produzindo ciências. 2009. Disponível

em:<http://produzindociencias.blogspot.com.br/2009_05_01_archive.html> Acesso em: 30 ago. 2014.

ROCHA, G. Dinâmicas para o dia do meio ambiente. 2012. Disponível em:

<http://gutarocha.blogspot.com.br/2012/06/dinamicas-para-o-dia-do-meioambiente.html>. Acesso em: 30 ago. 2014.

SANTOS, G. P. et al. Aulas práticas: importância dessa ferramenta dinamizadora para as aulas de geografia na Escola Estadual Américo Martins. 2013. Trabalho realizado no VII FEPEG/UNIMONTES. Disponível em:

<http://pibidamerico2014.blogspot.com.br/2014/04/trabalho-realizado-no-vii.html>. Acesso em: 25 ago. 2014.

SERAFIM, M.C. A Falácia da Dicotomia Teoria-Prática. Revista Espaço Acadêmico, Maringá, v.1, n.7, dez. 2001. Disponível em:

<http://www.espacoacademico.com.br/007/07mauricio.htm>. Acesso em: 30 ago. 2014. 